\title{
Thermal Model of a Tea Container under Solar Concentration Effect
}

\author{
K. Mahdi and N. Bellel
}

\begin{abstract}
Our paper focuses on the study of solar concentration with a new application that is to prepare the tea Concentrating solar power using a paraboloid (satellite television antenna) covered by a reflective material, stainless steel container cylindrical suspended arms of the parabola such that the focal point of the reflector or on the bottom of the container.

A theoretical model shows the behavior and the thermal equilibrium of the water in the container. The operation of the prototype shows that it takes 30 to 40 minutes to prepare tea. The results of our theoretical study were confronted and confounded with other published results in this area.
\end{abstract}

Keywords - solar concentrator, container, tea, heat transfer.

\section{INTRODUCTION}

Tea is a stimulating drink obtained by infusion of tea leaves, predried and usually oxidized. Originally, from China, it is now among the most drinkable beverage in the world. The most common method of preparation is brewing in a teapot (container) with a hot water between $70^{\circ} \mathrm{C}$ and $90^{\circ} \mathrm{C}$, according to the different categories of tea. Making tea from a polluting source (gas, wood, etc.) is harmful to the environment. Therefore, the use of solar energy, renewable and non-polluting, is an option to consider in the preparation of tea. The field of solar concentration does not require a significant investment and is protective of the environment (zero $\mathrm{CO}_{2}$ production in the atmosphere). The solar concentrator is a system concentration based on the capture of light radiation emitted by the sun. Their transformations into heat and its use for heating or cooking food differs depending on the geometry of the hub which may have various shapes (conical, paraboloidal, cylindrical etc.). It is a portable and lightweight, practical and useful for the Bedouin, campers and nomads who often travel in regions where solar energy is abundant. The objective of this work is to propose a tea brewing system with a parabolic antenna available in the commercial market, used for receiving TV channels via satellite. The surface of the antenna is covered by a reflective surface (aluminum foil) acting as a mirror. The base of the water-containing vessel is placed at the focal point of the parabola. The concentrated radiation to the focal point will heat the water with which the tea melting point temperature is

Manuscript received Sept. 9, 2015. (Write the date on which you submitted your paper for review.) This work was supported in part by the U.S. Department of Commerce under Grant BS123456 (sponsor and financial support acknowledgment goes here).

Khaled MAHDI is with the University des Frères Mentouri Constantine 1, ALGERIA.

Nadir BELLEL was with the University des Frères Mentouri Constantine 1, ALGERIA reached after a certain time. (Figure 1). The study of the thermal balance in many articles leads to a differential equation of temperature. The solution to this differential equation, gives the spatio-temporal evolution of the temperature of the water in the container, using the method of finite differences.

\section{DESCRIPTION OF OPERATING SYSTEM}

The rays from the sun are reflected by the satellite dish on the container of the tea, the concentrated solar radiation hits the bottom of the container, then the steel absorbs the concentrated energy that was covered by a matte black bottom, the water is in contact with the plate receive this energy concentrated by the transfer of heat by conduction, then we have a propagation of heat by the phenomenon of diffusion its direction upwards container, plus the change in density water causes water movement up by buoyancy, it may possibly passed through the phase change process if the cross inflection temperature (saturation). The concentration system essentially consists of a satellite receiver dish covered the inside surface foil rests on a metallic support positioned on the ground.

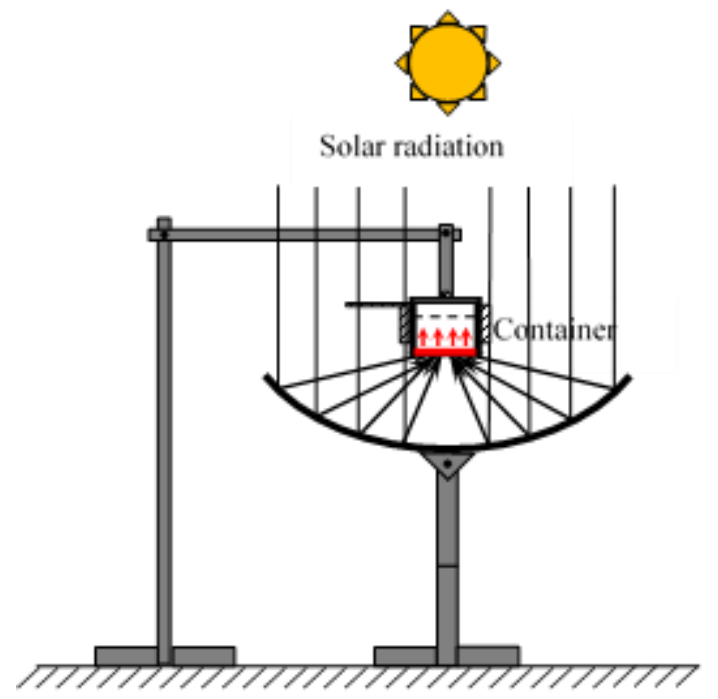

Fig. 1. Solar noon horizontal orientation where the major concentration.

A $10 \mathrm{~cm}$ diameter stainless steel vessel containing drinking water to prepare tea. This container surrounded by an insulating layer to minimized the lateral thermal losses of the container. Its base is covered with a flat black paint to reduce the reflection of rays concentrated by the reflector that has been placed in the home hub. 


\section{Heat Balance In Container LeVel}

The model is from a heat balance performed on the system shown in Figure 2.

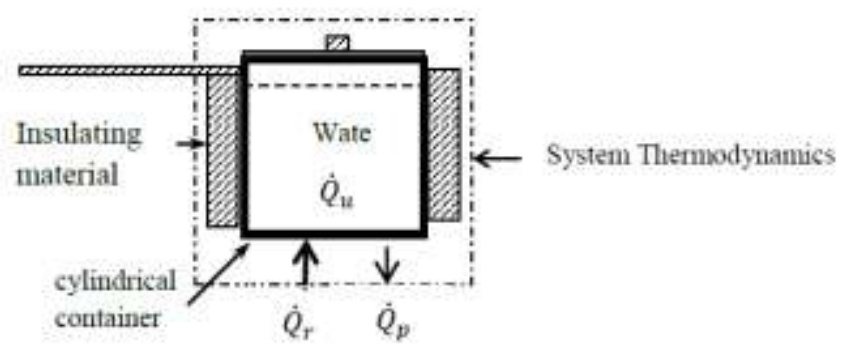

Fig. 2. The heat balance vessel.

The system consists of a cylindrical stainless steel container containing water. According to the assumptions proposed summers, the heat balance its general form is given by:

$$
\phi_{u}=\phi_{r}-\phi_{p}
$$

The output power is instantaneous change in internal energy of the system, the energy per unit time that reaches the lower limit of the system.

$$
\phi_{u}=\left(m_{\text {inox }} C p_{\text {inox }}+m_{\text {eau }} C C_{\text {eau }}\right) \frac{d T(t)}{d t}
$$

The solar radiation power concentrate provided by the parabolic antenna-container system is given by the following formula:

$$
Q_{r}=C_{g \eta_{\text {opt }}} A_{g} I_{0}(t)
$$

The presentation of daily solar radiation of the city of Constantine (see Figure 3), we used the model Jordan Liu [7]

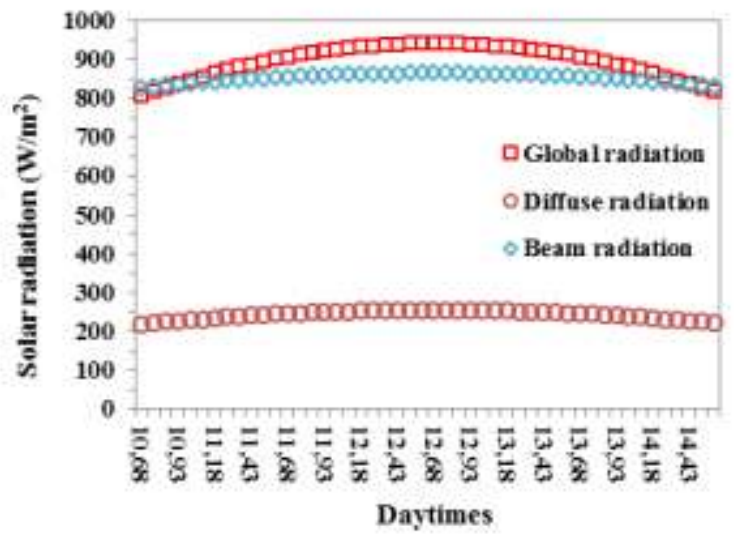

Fig. 3. Change of influence of the city of Constantine by Liu Jordan model [9].

The optical yield is given by the following formula:

$$
\eta_{\text {opt }}=\Gamma \propto \tau \rho
$$

$\Gamma$ is the intercept section, $\alpha$ is the absorptivity of the container surface, $\tau$ is the transitivity of the surface which collects the incident radiation and $\rho$ reflexivity of the parabolic antenna, the geometrical concentration factor of the antenna, which is dimensionless and is defined as the surface of the concentrator on the surface of the concentrated image that appears on the base of the container. The calculation of the solar radiation incident Io (t) is given using the model of Liu Jordan (Lambert Law).

Instantly varies along the day with not a minute. The heat losses of the system can be divided into three types, by conduction, convection and radiation. The first type is very small as the thickness of contact in stainless steel is very low, therefore conduction losses are negligible, for convection losses, we use Newton's law, and for the radiative losses, we use the Stefan Boltzmann equation given by the formula :

$$
\phi_{p}=h A_{e}\left[T(t)-T_{\mathrm{se}}\right]+\varepsilon \sigma\left[T(t)^{4}-T_{\text {ciel }}^{4}\right]
$$

Where $h$ is the heat transfer coefficient of the heat by convection $\left(\mathrm{W} / \mathrm{m}^{2} \mathrm{~K}\right)[3]$ between the coffee container and the environment, $A_{c}$ represents the outer surface of container $\left(\mathrm{m}^{2}\right)$, $T(t)$ is the instantaneous temperature of the thermodynamic system $\left({ }^{\circ} \mathrm{C}\right), \varepsilon$ is the emissivity of container (Aluminium), $\sigma$ is the constant of Stefane-Boltzmann $\left(5.67 \times 10^{-8} \mathrm{~W} / \mathrm{m}^{2} \mathrm{~K}^{4}\right)$ and $T_{\text {ciel }}$ is the sky temperature for practical reason we replace this temperature depending on the temperature of the environment $T_{\infty}$ par the following formula:

$$
T_{\text {ciel }}=T_{\mathrm{sec}}-6
$$

Values used in the theoretical model program

TABLE 1. THERMOPHYSICAL AND OPTICAL PROPERTIES OF THERMODYNAMIC SYSTEM

\begin{tabular}{ccc}
\hline \hline & Value & unit \\
\hline \hline$A_{s}$ & 0,01 & $m^{2}$ \\
$A_{c}$ & 0,636 & $m^{2}$ \\
$c_{\text {peau }}$ & 4190 & $W / m^{2} K$ \\
$c_{\text {pinox }}$ & 460 & $W / m^{2} K$ \\
$m_{w}(t)$ & 0,3 & $k g$ \\
$m_{A l}$ & 0,2 & $k g$ \\
$T_{\text {ses }}$ & - & ${ }^{\circ} \mathrm{C}$ \\
$\alpha$ & 0,95 & - \\
$\rho$ & 0,8 & - \\
$\varepsilon$ & 1 & - \\
$\sigma$ & $5,67 \mathrm{e}-08$ & $\mathrm{~W} / \mathrm{m}^{2} \mathrm{~K}$ \\
$C_{g}$ & {$[7-9]$} & - \\
$U_{g l o b}$ & 25 & $\mathrm{~W} / \mathrm{m}^{2 \circ} \mathrm{C}$
\end{tabular}

We calculate the temperature of the captive of the absorber surface from the equation (1) after the previous calculations, the equation becomes [7], and we find the following equation: 


$$
\begin{aligned}
T(t)=T_{\mathrm{sc}} & +\frac{\eta_{\text {opt }} I_{0}(t) C_{g}}{U_{g l o b}}-\left(\frac{\eta_{\text {opt }} I_{0}(t) C_{g}}{U_{g l o b}}-T\left(t_{0}\right)+T_{\mathrm{sc}}\right) \times \\
& \exp \left\{-\left[\frac{U_{g l o b} A_{c}}{m c}\left(t-t_{0}\right)\right]\right\}
\end{aligned}
$$

\section{RESULT AND INTERPRETATION}

The antenna must be positioned and oriented to the sun throughout the preparation of tea, temperature increases rapidly in the container based on concentrated solar radiation to heat transfer by conduction to adjacent the base fluid is more important at walls.
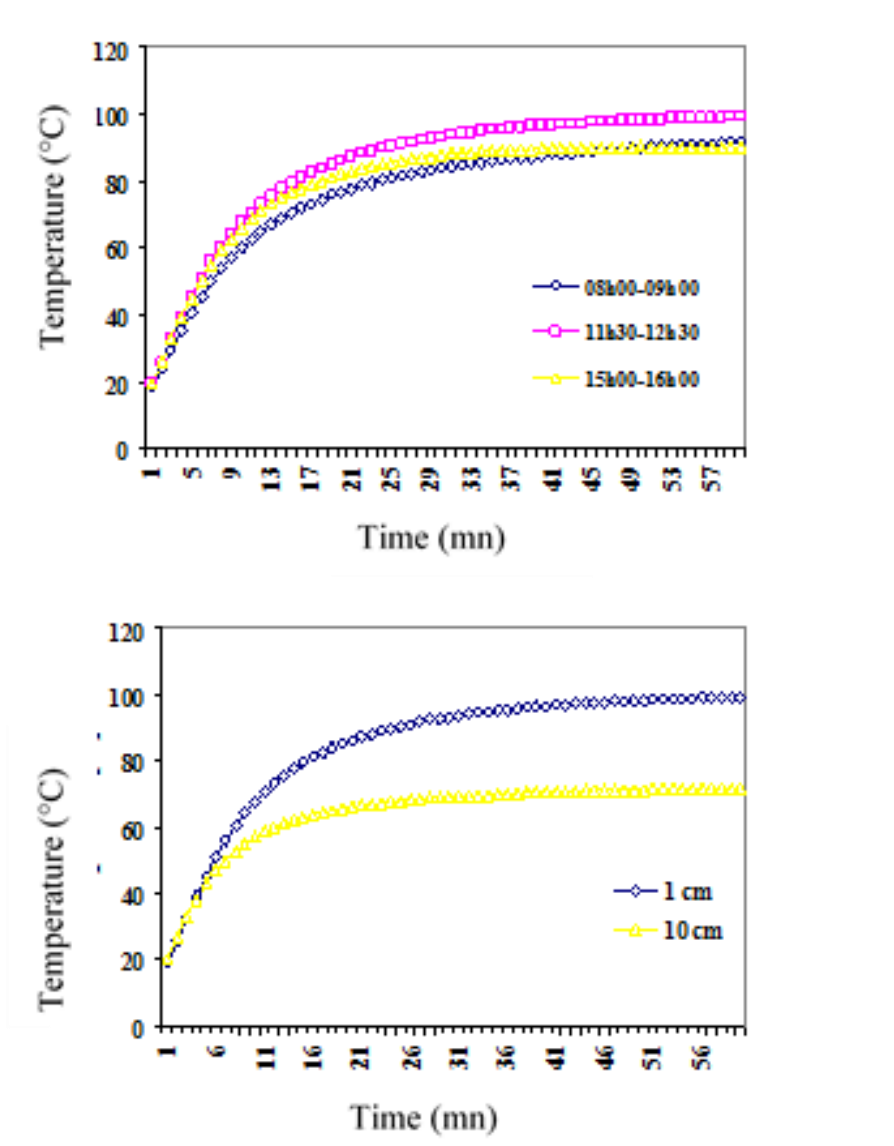

Fig. 4. Evolution of the container temperature for different times of the day (left), Climate Change between the top and bottom of the container between 11h.30-12h.30.

In Figure 4, We can point to the level located at $1 \mathrm{~cm}$ from the base of the container temperature is a constant evolution until the value of $95^{\circ} \mathrm{C}$, at which we notice that the scheme is established and therefore the temperature varies slightly, and the level that is located $10 \mathrm{~cm}$ from the base of the container temperature is a constant evolution until the value of $70{ }^{\circ} \mathrm{C}$, then the regime is established. The change in thermal powers at the container.

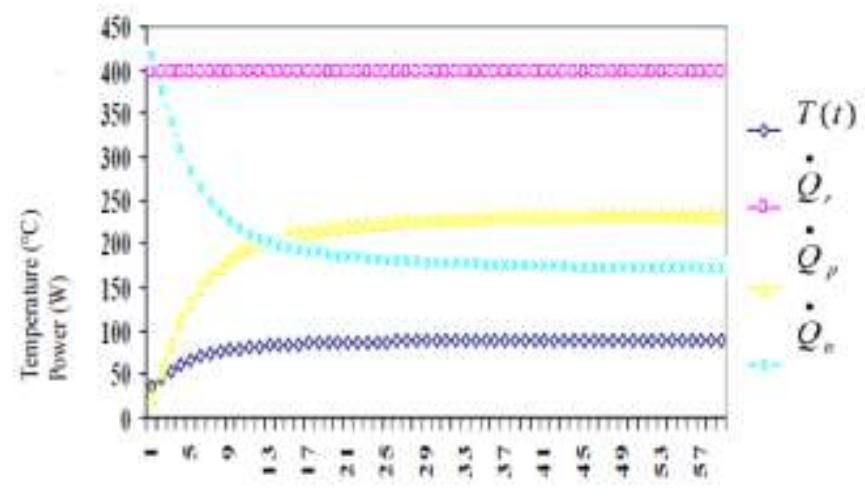

Time (mn)

Fig. 5. Representation of different Powers from 11:30 to 12:30 Wind equal to $5 \mathrm{~m} / \mathrm{s}$ (left) and $2 \mathrm{~m} / \mathrm{s}$ (right)

The theoretical calculation of the evolution of power shown in Figure 5. For the two different wind speeds, we see a direct influence on the inflection point temperature, so for fairly large wind speeds heat loss are important and by comparison with other developed work [1], the container is very sensitive to wind speed.

\section{CONCLUSION}

Predicting the temperature at the container for preparing tea, depends on several factors, the most important is the intensity of solar radiation, the diameter, the quality of mirror of the satellite dish and wind speed. These factors impact and direct influence on the evolution of the temperature of the water inside the container. We note that the scheme is built around a temperature of $85^{\circ} \mathrm{C}$ (brewing tea). As well as the identification of the stratification of the temperature at the heated fluid from the bottom, up. The theoretical model may describe the evolution of the temperature of the water in the container at all levels from bottom to top. The time for the preparation of tea is between 30-40 min. Even low solar radiation. This is because the concentration factor of the parabolic antenna is not sufficient for rapid heating process.

\section{REFERENCES}

[1] Agarwal, R. and Karahanna, E. (2000) Time flies when you're having fun: Cognitive absorption and beliefs about information technology usage, MIS Quarterly, 24, 4, 665-694. https://doi.org/10.2307/3250951

[2] Ajzen, I. (1988) Attitudes, personality, and behavior, The Dorsey Press, Chicago.

[3] Incropera FP, DeWitt DP. Fundamentals of heat and mass transfer. $5 \mathrm{th}^{\mathrm{ed}}$. Wiley; 2001.

[4] Ajzen, I. (1991) The theory of planned behavior, Organizational Behavior \& Human Decision Processes, 50, 2, 179-211. https://doi.org/10.1016/0749-5978(91)90020-T

[5] Ghani, J. A., Supnick, R. and Rooney, P. (1991) The experience of flow in computer-mediated and in face-to-face groups, in Janice DeGross, Izak Benbasat, Gerardine DeSanctis and Cynthia Mathis Beath (Eds.) Proceedings of the Twelfth International Conference on Information Systems, December 16-18, New York, NY, USA, University of Minnesota, 229 - 237.

[6] Tractinsky, N. (1997) Aesthetics and apparent usability: Empirically assessing cultural and methodological issues, in Steve Pemberton (Ed.) Proceedings of the SIGCHI conference on Human factors in computing 
systems (CHI 97), March 22 - 27, Atlanta, GA, USA, ACM Press, 115-122.

https://doi.org/10.1145/258549.258626

[7] O. C. Jorgensen, (1982) Collector heat capacity effect on solar system performance, Solar Energy. Vol29. No.2. pp 175-176, Printed in Great Britain.

https://doi.org/10.1016/0038-092X(82)90180-3

http://www.eso.org/gen-fac/pubs/astclim/espas/world/ION/ion-pwv.html

Authors' information

Energy Physics Laboratory, University Mentouri-Constantine, 25005

Constantine, Algeria

Pr. Nadir BELLEL Was born in 1955 in Constantine, Algeria. He received his Doctorat Degree in 2005 from the University Mentouri-Constantine. His main interest of research concerns the Energy, Renewable Energy. Actually, he is a teacher-Associate Professor, Director of Energy Physical Research Laboratory and Director of journal publishing at the University Mentouri-Constantine. 